\title{
Potentiation of the effects of chlorhexidine diacetate and cetylpyridinium chloride on mycobacteria by ethambutol
}

\author{
S. J. BROADLEY, P. A. JENKINS*, J. R. FURR and A. D. RUSSELL $\dagger$ \\ Welsh School of Pharmacy, University of Wales, Cardiff, King Edward VII Avenue, Cardiff CF1 $3 X F$ and \\ - Mycobacterium Reference Unit, Public Health Laboratory Service, University Hospital of Wales, Heath Park, \\ Cardiff CF $4 \times W$
}

\begin{abstract}
Summary. Ethambutol enhanced the effects of chlorhexidine diacetate and cetylpyridinium chloride against Mycobacterium avium, $M$. bovis BCG, $M$. fortuitum and $M$. phlei. The findings show that it is possible to increase the susceptibility of mycobacteria to agents that normally exhibit poor activity against these organisms because of their reduced cellular penetration.
\end{abstract}

\section{Introduction}

The antiseptics chlorhexidine diacetate and cetylpyridinium chloride have poor mycobactericidal activity, ${ }^{1}$ probably because the cell wall acts as a barrier to their penetration into the cell. The search for new antibacterial compounds with low toxicity and activity at low concentration has intensified because of the restrictions imposed on the use of aldehydes as disinfectants and the increasing prevalence of mycobacterial infections in AIDS patients and the homeless. This study was undertaken to determine whether it is possible to increase the activity of the two antiseptics in the presence of ethambutol, an anti-tubercular agent that enhances the activity of a wide range of drugs against mycobacteria. ${ }^{2}$ Some preliminary observations have been reported previously. ${ }^{3}$

\section{Materials and methods}

Mycobacterium fortuitum ATCC 6841, M. bovis BCG (NCO 5692), $M$. phlei NCTC 8151 and laboratory isolate 3906 of $M$. avium were grown at $37^{\circ} \mathrm{C}$ on Löwenstein-Jensen slopes.

Minimum inhibitory concentrations (MICs) of chlorhexidine diacetate (Sigma), cetylpyridinium chloride (BDH) and ethambutol (Lederle) were estimated in Middlebrook 7H9 liquid medium. Ten-ml volumes of medium, containing the desired concentrations of biocides, were inoculated with $20 \mu$ l of a

Received 28 March 1995; revised version accepted 17 May 1995. † Correspondence should be sent to Professor A. D. Russell. test culture, prepared by mixing a loopful of bacteria from a culture on a Löwenstein-Jensen slope in a 7-ml screw-capped bottle with $0.75 \mathrm{ml}$ of phosphate buffer and two small nails, and stirring until an even suspension was obtained. Presence or absence of visible growth was noted after incubation at $37^{\circ} \mathrm{C}$ for 10 days. MICs of test biocides were also assessed in the presence of ethambutol $(0 \cdot 5-10 \mathrm{mg} / \mathrm{L})$.

To study the effects of pre-treatment with ethambutol, heavy suspensions of cells were exposed to ethambutol, 1 or $12.5 \mathrm{mg} / \mathrm{L}$ in $10 \mathrm{ml}$ of sterile distilled water and held at room temperature for $20 \mathrm{~min}, 60 \mathrm{~min}$ or $24 \mathrm{~h}$. The suspensions were washed twice by centrifugation and used to prepare inocula for MIC determinations as described above. Control suspensions were subjected to the same procedure but without ethambutol.

Possible interactions between ethambutol and biocides were also examined in the Bactec 460 radiometric system in which ${ }^{14} \mathrm{C}$-labelled $\mathrm{CO}_{2}$ is generated by the metabolism of a ${ }^{14} \mathrm{C}$-labelled substrate in Middlebrook 7H12 medium. Various concentrations of the chemicals were added to this medium and the growth (radiometric "growth index") of the organisms at $37^{\circ} \mathrm{C}$ was recorded daily for up to 30 days.

\section{Results}

MICs of the test compounds for the four strains of mycobacteria are shown in the table.

Pre-treatment of a washed suspension of $M$. bovis BCG or $M$. avium 3906 with ethambutol $1 \mathrm{mg} / \mathrm{L}$, or $M$. fortuitum ATCC 6841 or $M$. phlei NCTC 8151 
a

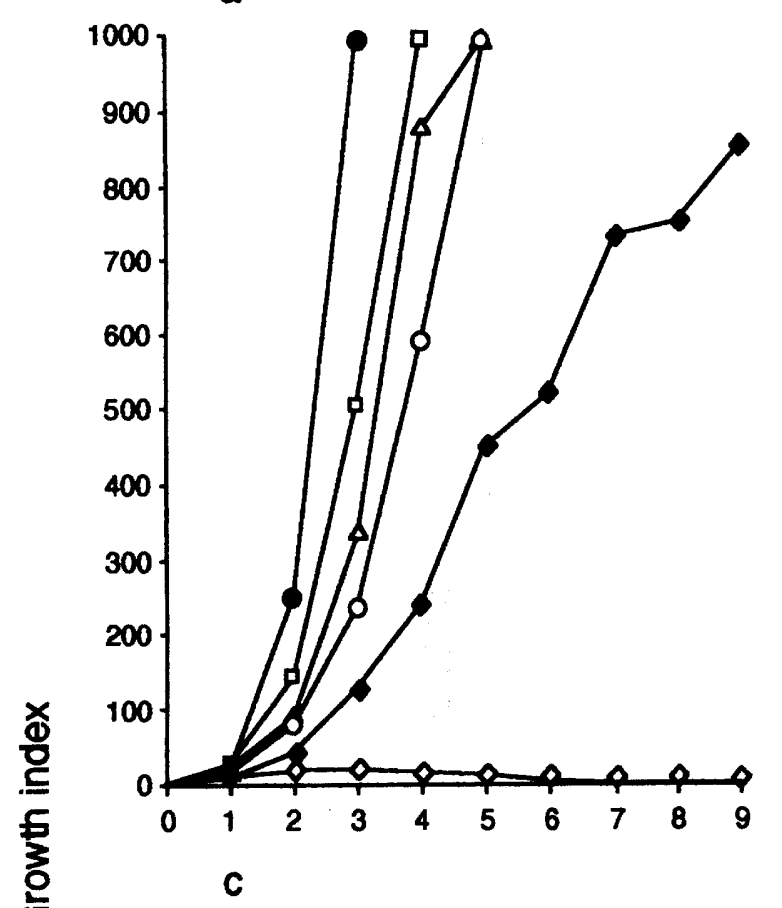

C

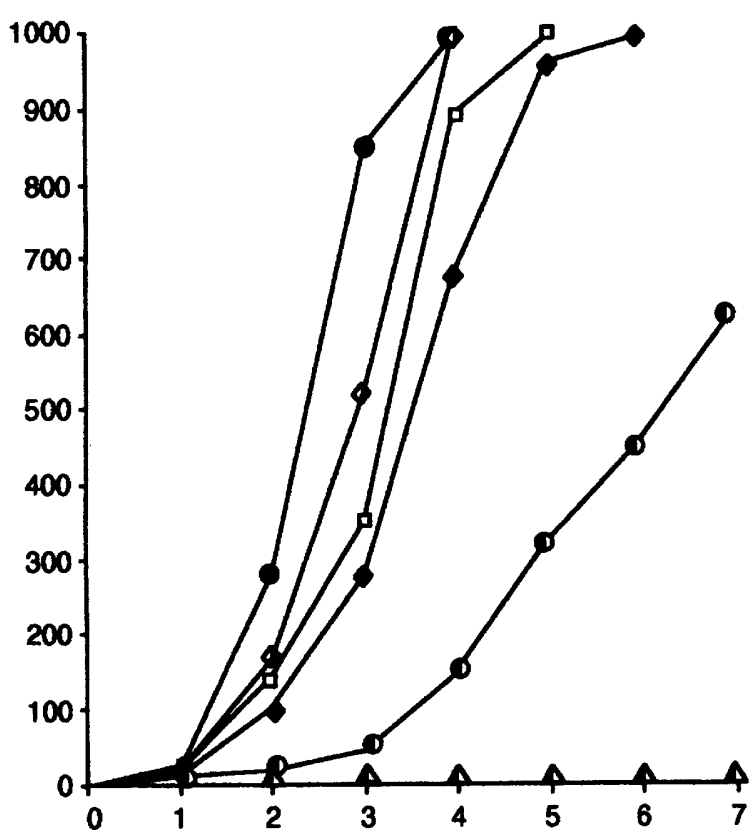

b

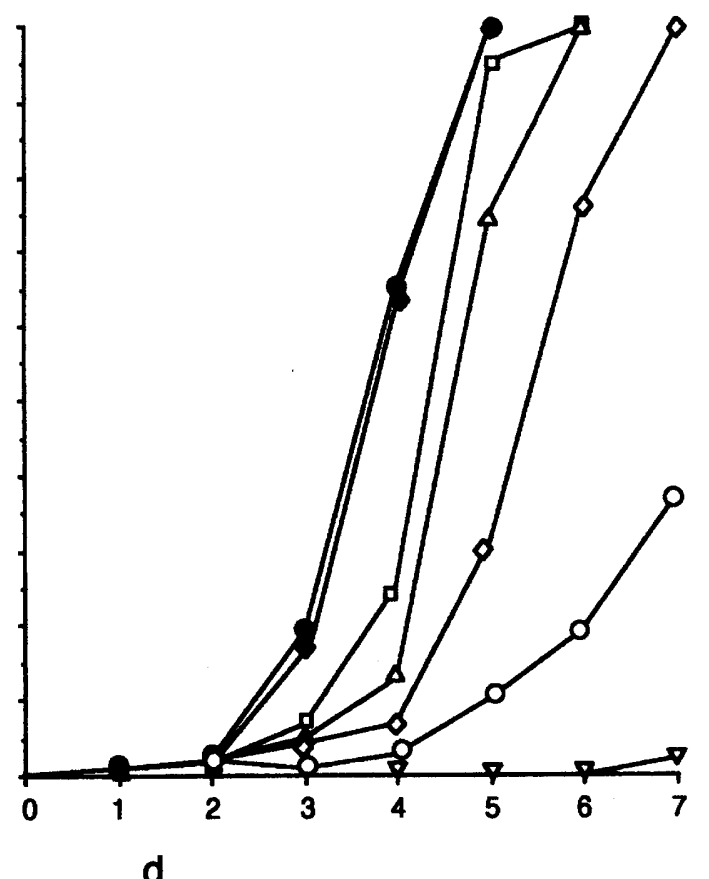

d

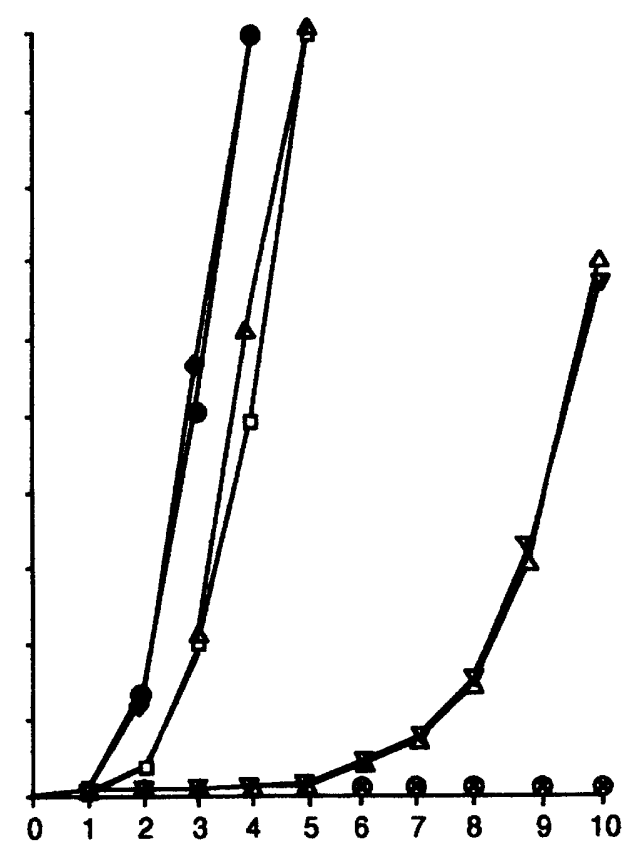

Time (days)

Figure. Effect of ethambutol and biocides, alone and in combination on the growth of $M$. avium 3906 at $37^{\circ} \mathrm{C}$ as measured radiometrically. a:, control; $\diamond$, ethambutol $1 ; \square$ chlorhexidine $10 ; \triangle$, chlorhexidine $25 ; O$, chlorhexidine $50 ; \diamond$, ethambutol 1 plus chlorhexidine 1. b: , control; $\triangleleft$, ethambutol $0 \cdot 1 ; \square$, chlorhexidine $10 ; \triangle$, chlorhexidine $25 ; \bigcirc$, chlorhexidine $50 ; \diamond$ ethambutol $0 \cdot 1$ plus chlorhexidine $1 ; \nabla$, ethambutol $0 \cdot 1$ plus chlorhexidine 2.5 . c: $\bigcirc$, control; $\diamond$, ethambutol $0.5 ; \diamond$, cetylpyridinium $5 ; \square$, cetylpyridinium $10 ; 0$ ethambutol 0.5 plus cetylpyridinium $5 ; \triangle$, ethambutol 0.5 plus cetylpyridinium 10 . d: $\bigcirc$, control; $\diamond$, ethambutol $0 \cdot 1 ; \square$, cetylpyridinium $10 ; \triangle$, cetylpyridinium $25 ; \bigcirc$, cetylpyridinium $50 ; \Delta$, ethambutol 0.1 plus cetylpyridinium $10 ; \nabla$, ethambutol $0 \cdot 1$ plus cetylpyridinium $25 ; \times$, ethambutol $0 \cdot 1$ plus cetylpyridinium 50 . All concentrations in $\mathrm{mg} / \mathrm{L}$.

with ethambutol $12.5 \mathrm{mg} / \mathrm{L}$, had no effect on the MICs of chlorhexidine or cetylpyridinium.

MICs of chlorhexidine for $M$. fortuitum and $M$. phlei were slightly reduced in medium containing ethambutol $10 \mathrm{mg} / \mathrm{L}$. In the presence of ethambutol $1 \mathrm{mg} / \mathrm{L}$ the MIC of chlorhexidine for the BCG strain of $M$. bovis decreased from $2.5-5 \mathrm{mg} / \mathrm{L}$ to $1 \mathrm{mg} / \mathrm{L}$. The MIC of cetylpyridinium for $M$. avium fell from
$50 \mathrm{mg} / \mathrm{L}$ to $10 \mathrm{mg} / \mathrm{L}$ in the presence of ethambutol $0.5 \mathrm{mg} / \mathrm{L}$.

In radiometric experiments, chlorhexidine alone at concentrations of 10,25 and $50 \mathrm{mg} / \mathrm{L}$ or ethambutol alone at a concentration of $1 \mathrm{mg} / \mathrm{L}$ slightly reduced the rate of growth of $M$. avium. A combination of chlorhexidine $1 \mathrm{mg} / \mathrm{L}$ and ethambutol $1 \mathrm{mg} / \mathrm{L} \mathrm{com-}$ pletely inhibited growth (figure a). 
Table. Inhibitory concentrations of test compounds, alone and in combination, against four strains of mycobacteria

\begin{tabular}{|c|c|c|c|c|c|c|}
\hline \multirow{2}{*}{ Test strain } & \multicolumn{6}{|c|}{$\mathrm{MIC}(\mathrm{mg} / \mathrm{L})$} \\
\hline & ETH & CHA & $\begin{array}{c}\text { CHA+ } \\
\text { ETH }(1 \mathrm{mg} / \mathrm{L})\end{array}$ & $\begin{array}{c}\mathrm{CHA}+ \\
\text { ETH }(10 \mathrm{mg} / \mathrm{L})\end{array}$ & CPC & $\begin{array}{c}\text { CPC }+ \\
\text { ETH }(0.5 \mathrm{mg} / \mathrm{L})\end{array}$ \\
\hline $\begin{array}{l}\text { M. fortuitum } \\
\text { ATCC } 6841\end{array}$ & 25 & $1-2 \cdot 5$ & NT & 0.5 & $25-50$ & NT \\
\hline $\begin{array}{l}\text { M. bovis } \\
\text { NCO } 5692\end{array}$ & $2 \cdot 5$ & $2 \cdot 5-5$ & 1 & NT & $10-25$ & NT \\
\hline $\begin{array}{l}\text { M. phlei } \\
\text { NCTC } 8151\end{array}$ & 25 & $0 \cdot 5-1$ & NT & $<0.5$ & $5-10$ & NT \\
\hline M. avium 3906 & 5 & 50 & 1 & NT & $25-50$ & 10 \\
\hline
\end{tabular}

ETH, ethambutol; CHA, chlorhexidine diacetate; CPC, cetylpyridinium chloride; NT, not tested.

When the experiment was repeated with ethambutol at a lower concentration of $0.1 \mathrm{mg} / \mathrm{L}$, the drug alone did not reduce the growth rate of $M$. avium but it greatly enhanced the effect of chlorhexidine. Ethambutol $0.1 \mathrm{mg} / \mathrm{L}$ with chlorhexidine $2.5 \mathrm{mg} / \mathrm{L}$ completely suppressed growth for 7 days (figure b).

In similar experiments with cetylpyridinium chloride, ethambutol $0.5 \mathrm{mg} / \mathrm{L}$ (figure c) but not $0.1 \mathrm{mg} / \mathrm{L}$ (figure d) enhanced inhibition of growth by the biocide. Growth was completely inhibited by ethambutol $0.5 \mathrm{mg} / \mathrm{L}$ with cetylpyridinium $10 \mathrm{mg} / \mathrm{L}$ or by ethambutol $0.1 \mathrm{mg} / \mathrm{L}$ with cetylpyridinium $50 \mathrm{mg} / \mathrm{L}$, although the quaternary ammonium compound alone was inhibitory at this concentration.

\section{Discussion}

Chlorhexidine and cetylpyridinium chloride have little mycobacterial activity, ${ }^{1}$ but low concentrations are mycobacteristatic (table). This suggests that the compounds traverse the mycobacterial cell wall in sufficient concentration to inhibit growth but not to kill the organisms. It is likely that the cytoplasmic membrane is the target site of chlorhexidine and cetylpyridinium in mycobacteria as it is in other bacteria, although evidence is lacking.

\section{References}

1. Russell AD. Mycobactericidal agents. In: Russell AD, Hugo WB, Ayliffe GAJ (eds). Principles and practice of disinfection, preservation and sterilization, 2nd edn. Oxford, Blackwell Scientific Publications. 1992: 246-253.

2. Rastogi N, Goh KS, David HL. Enhancement of drug susceptibility of Mycobacterium avium by inhibitors of cell envelope synthesis. Antimicrob Agents Chemother 1990; 34: 759-764.

3. Russell AD, Broadley SJ, Furr JR, Jenkins PA. Potentiation of the antimycobacterial activity of biocides. $J$ Infect 1994 28: $108-109$.

4. Inderlied CB, Kemper CA, Bermudez LEM. The Myco-
Ethambutol is used in combination with other antimycobacterial drugs in chemotherapeutic regimens. It has been reported to enhance the activity of rifampicin, ciprofloxacin and ofloxacin. ${ }^{2}$ In the present study, low concentrations of ethambutol potentiated the activity of the biocides chlorhexidine diacetate and cetylpyridinium chloride against $M$. avium.

Three insoluble macromolecular components (arabinogalactan, peptidoglycan and mycolic acids) are present in the cell wall of mycobacteria together with C-mycoside glycopeptidolipids. ${ }^{4}$ The mycolic acids comprise $c .50 \%$, by weight, of the mycoylarabinogalactan peptidoglycan core ${ }^{4}$ and undoubtedly contribute to reduced permeability to hydrophilic molecules. ${ }^{5-7}$. How ethambutol potentiates the activity of biocides is unclear; however, it is likely that the drug "opens up" the mycobacterial cell wall allowing greater penetration of these biocides to their target sites within the cell.

It would be instructive to examine the antimycobacterial effects of these, and other, biocides with agents that inhibit mycolic acid biosynthesis ${ }^{2,7}$ and with compounds such as $m$-fluoro-DL-phenylalanine, which is a potent inhibitor of mycoside $C$ biosynthesis. $^{2}$

We thank the Department of Health for a research studentship to S.J.B.

bacterium avium complex. Clin Microbiol Rev 1993; 6: 266-310.

5. Jarlier V, Nikaido H. Permeability barrier to hydrophilic solutes in Mycobacterium chelonei. $J$ Bacteriol 1990; 172: 1418-1423.

6. Wheeler PR, Besra GS, Minnikin DE, Ratledge C. Inhibition of mycolic acid biosynthesis in a cell-wall preparation from Mycobacterium smegmatis by methyl 4-(2-octadecylcyclopropen-1-yl) butanoate, a structural analogue of a key precursor. Lett Appl Microbiol 1993; 17: 33-36.

7. McNeil MR, Brennan PJ. Structure, function and biogenesis of the cell envelope of mycobacteria in relation to bacterial physiology, pathogenesis and drug resistance: some thoughts and possibilities arising from recent structural information. Res Microbiol 1991; 142: 451-463. 